\title{
Chasing the Chameleon: Psychogenic Paraparesis Responding to Non-Invasive Brain Stimulation
}

\author{
Simona Portaro ${ }^{1}$, Demetrio Milardi ${ }^{1,2}$, Antonino Naro ${ }^{1}$, Antonio Chillura ${ }^{1}$, \\ Francesco Corallo ${ }^{1}$, Angelo Quartarone ${ }^{1,2}$, and Rocco Salvatore Calabrò ${ }^{1 凶}$ \\ ${ }^{1}$ IRCCS Centro Neurolesi "Bonino-Pulejo", Messina, Italy \\ 2Department of Biomedical, Dental Sciences and Morphological and Functional Images, University of Messina, Messina, Italy
}

\begin{abstract}
Neurologic symptoms that develop unconsciously and are incompatible with known pathophysiologic mechanisms or anatomic pathways belong to Conversion Disorder (CD). CD diagnosis is based on the clinical history and the exclusion of physical disorders causing significant distress or social and occupational impairment. In a subgroup of CD, called functional weakness (FW), symptoms affecting limbs may be persistent, thus causing a permanent or transient loss of limb function. Physiotherapy, pharmacotherapy, hypnotherapy and repetitive transcranial magnetic stimulation (rTMS) have been proposed as treatment strategies for FW-CD. Herein, we report a 30 year-old male, presenting with lower limb functional paraparesis, having obtained positive, objectively, and stable effects from a prolonged r-TMS protocol associated to a multidisciplinary approach, including psychological and sexuological counseling, and monitored by gait analysis. We postulate that our rTMS protocol, combined with a multidisciplinary approach may be the proper treatment strategy to improve FW-CD.

Psychiatry Investig 2018;15(4):428-431
\end{abstract}

Key Words Functional weakness, Conversion disorder, Repetitive Transcranial Magnetic Stimulation (r-TMS), Multidisciplinary approach, Treatment strategies.

\section{INTRODUCTION}

Neurologic symptomatology that develops unconsciously and is not related to known pathophysiologic mechanisms or anatomic pathways is called Conversion Disorder (CD), which is actually classified under the "Functional Neurological Symptom Disorder" (FNS) in the DSM-5. ${ }^{1}$ CD diagnosis is mainly based on the exclusion of physical disorders causing significant distress or social and occupational impairment. CD incidence is between 4 and 12 cases per 100,000 habitants/year, although its exact prevalence is unknown. ${ }^{1}$ In a subgroup of $\mathrm{CD}$, called functional weakness or paralysis (FW) (DSM-5 300.11/ICD-10 F44.4), symptoms affecting limbs may be persistent, thus causing a permanent or transient loss of limb function. ${ }^{1}$

Received: June 12, 2017 Revised: September 29, 2017 Accepted: October 16, 2017

$\triangle$ Correspondence: Rocco Salvatore Calabrò, $\mathrm{MD}, \mathrm{PhD}$

IRCCS Centro Neurolesi “Bonino-Pulejo," Via Palermo, SS 113 C.da Casazza Messina, Italy

Tel: +39 09060128840, Fax: +39 09060128854, E-mail: salbro77@tiscali.it

(c) This is an Open Access article distributed under the terms of the Creative Commons Attribution Non-Commercial License (http://creativecommons.org/licenses/bync/4.0) which permits unrestricted non-commercial use, distribution, and reproduction in any medium, provided the original work is properly cited.
Physiotherapy, pharmacotherapy, and hypnotherapy have been proposed as treatment strategies for FW-CD in the past years, ${ }^{2-4}$ showing a variable and heterogeneous symptoms recovery. Recently, it has been suggested that multidisciplinary approach including behavioral and motor learning programs could represent the most effective FW therapy. ${ }^{2}$ Besides, repetitive transcranial magnetic stimulation (rTMS) is currently used as an adjunctive treatment option in different neuropsychiatric conditions, including CD. ${ }^{5}$ Herein, we report the case of a 30 year-old male, who developed functional paraparesis due to psychological factors, rapidly and stably recovered by a multidisciplinary approach including rTMS.

\section{CASE}

The patient is a 30 year-old man, second child from nonconsanguineous parents, born preterm (at 32 weeks) by Caesarean section. He was in incubator for two weeks. Family history was unremarkable. He presented normal psychomotor milestones. From 10 to 18 years-old, he presented with a growth hormone deficit, treated with a replacement therapy. At our observation (October 2016), he complained of low back pain and gait difficulties, worsened by physical exercise, for about 
10 years. At neurological examination, the patient presented with paraparesis so that gait was possible only with two canes; muscle strength assessment was difficult to evaluate since he complained of intense low back pain. Nonetheless, no objective signs of the central and peripheral nervous system impairment were detected. Psychological evaluation showed depressed mood, marked anxiety, severe phobic cues with hypocondria, and poor emotional control, according to the Minnesota Multiphasic Personality Inventory-2 score (MMPI-2) ${ }^{6}$ and Hamilton Rating Scale for Depression (HRS-D) (score: 18). ${ }^{7}$

The sexual counselling did not point out any sexual dysfunction. The patient was in a stable homosexual relationship, but his sexual orientation disappointed his relatives. Indeed, the first ever time he presented the ambulation deficit was somehow related to his coming-out, and he had the main symptom exacerbation following family's quarrels over his sexuality. Because of these symptoms, he underwent several investigations, including brain and spinal cord MRI with contrast medium, hips and pelvis X-ray, a complete neurophysiological evaluation (multi-modal evoked potentials, electromyography), blood tests (including inflammatory and autoimmune markers and muscle enzymes dosages), all within the normal range.

Therefore, the patient was diagnosed with FW-CD and thus recruited for an rTMS treatment, which consisted of 100 stimuli at $100 \%$ maximum stimulator output, randomly delivered to the right and left primary motor cortex of the armhand and leg motor areas, at $1 \mathrm{~Hz}$, three times a week for three months. This protocol was adapted to the patient, employing the stimulation paradigms of previous studies (Table 1). The patient gave his written informed consent.

Psychological evaluation and gait-analysis were performed before (T0) and after the end (T1) of the rTMS protocol to evaluate rTMS after-effects. The gait analysis was performed by using the OptoGait system (Version 1.6.4.0, Microgate, Bolzano, Italy). ${ }^{8}$

T0, we found abnormal values of each phase of gait and the temporal parameters of the gait, i.e., gait cycle $(5,646 \pm 2.553 \mathrm{sec})$, cadence $(19 \pm 13.8 \mathrm{step} / \mathrm{min})$, and step time with a preservation of the step and stride length. The visual analogue scale (VAS) for low back pain yielded a score $7 / 10$.

At $\mathrm{T} 1$, the subject reported an improvement in mood and

Table 1. Comparison of the rTMS studies on FW-CD

\begin{tabular}{|c|c|c|c|c|}
\hline Study & FW patients & Clinical presentation & rTMS protocol & Outcome \\
\hline 14 & $\begin{array}{l}3 \text { (1 male) } \\
\text { about } 38 \text { years } \\
\text { of age }\end{array}$ & $\begin{array}{l}\text { Not detailed, since } \\
5 \text { weeks to } 5 \text { years }\end{array}$ & $\begin{array}{l}\text { M1 } \\
15 \mathrm{~Hz} \\
5 \text { times/week for } 2 \text { weeks } \\
110 \% \text { RMT then } 90 \% \text { RMT up to } \\
12 \text { weeks }\end{array}$ & Marked improvement \\
\hline 15 & $\begin{array}{l}70 \text { ( } 8-79 \text { years }) \\
\text { of age }\end{array}$ & $\begin{array}{l}55 \text { Acute } \\
\text { (since } 4 \text { days) } \\
15 \text { chronic } \\
\text { (since } 240 \text { days) }\end{array}$ & $\begin{array}{l}\text { M1 } \\
\text { iTBS } \\
1-2 \text { session in one day } \\
100 \% \text { MSO }\end{array}$ & Immediately or within hours in $89 \%$ \\
\hline 16 & $\begin{array}{l}1 \text { male, } 24 \text { years } \\
\text { of age }\end{array}$ & $\begin{array}{l}\text { Hemiparesis that } \\
\text { compromised } \\
\text { walking }\end{array}$ & $\begin{array}{l}\text { Vertex stimulation } \\
\text { Patterned rTMS* }\end{array}$ & $\begin{array}{l}\text { patient able to walk again independently, } \\
\text { immediately after }\end{array}$ \\
\hline 17 & $\begin{array}{l}1 \text { male, } 33 \text { years } \\
\text { of age }\end{array}$ & $\begin{array}{l}\text { Quadriplegia since } \\
6 \text { months }\end{array}$ & $\begin{array}{l}\text { Right and left M1-HAND and } \\
\text { M1-LEG } \\
1 \mathrm{~Hz} \\
5 \text { times/week for } 8 \text { weeks and, after, } \\
\text { twice a week }\end{array}$ & $\begin{array}{l}\text { Initially progressive amelioration; then, } \\
\text { further deterioration leading a new rTMS } \\
\text { with amelioration }\end{array}$ \\
\hline 18 & $\begin{array}{l}11 \text { ( } 4 \text { males), } \\
34-64 \text { years } \\
\text { of age }\end{array}$ & $\begin{array}{l}\text { Flaccid hand } \\
\text { paralysis since } 4 \\
\text { weeks to } 25 \text { years }\end{array}$ & $\begin{array}{l}\text { Contralateral M1 stimulation } \\
15 \mathrm{~Hz} \\
5 \text { times/week for } 2 \text { weeks }\end{array}$ & Improve in muscle strength \\
\hline $\begin{array}{l}\text { Our } \\
\text { case }\end{array}$ & $\begin{array}{l}1 \text { male, } 30 \text { years } \\
\text { of age }\end{array}$ & Flaccid paraparesis & $\begin{array}{l}\text { Right and left M1-HAND and } \\
\text { M1-LEG } \\
1 \mathrm{~Hz} \\
3 \text { times/week for } 3 \text { months } \\
100 \% \text { MSO }\end{array}$ & Marked improvement up to resolution \\
\hline
\end{tabular}

*single rTMS session with 12 single pulses at initially 30\% maximal stimulator output intensity and increasing I in $10 \%$ steps up to $80 \%$ of maximal stimulator output. MSO: maximal stimulator output, TBS: theta-burst stimulation, RMT: resting motor threshold 
anxiety (HRS-D: 7), hysteria and hypochondria items of the MMPI-2, and lower limb "weakness" with pain relief (VAS $3 / 10$ ), being thus able to walk independently. We also found a significant improvement in the spatial, and temporal gait parameters (gait cycle: $1,707 \pm 1.2 \mathrm{sec}$; cadence $68.4 \pm 18.4$ step/min).

\section{DISCUSSION}

FW-CD has a still not known underlying etiological mechanism. Although the former criterion contained in DSM-IV considered psychological factors as essential to perform FW$\mathrm{CD}$ diagnosis, actually the DSM-V removed this aspect, considering that FW-CD are caused by a neurobiological component, even though stressful events may be possible causal concomitant factors influencing patients' vulnerability. ${ }^{10}$

Treating FW-CD disorders using TMS was firstly postulated by Jellinek et al. in the nineties. ${ }^{11}$ Few years later, other authors showed that rTMS induces long-lasting clinical improvement by stimulating cortical areas and inducing changes in cortical excitability and the interconnected brain areas, even in FWCD patients. ${ }^{12}$ The supporting available literature on the use of rTMS in FW-CD is very sparse, so any assumption of a beneficial effect needs to be seen with caution. Recently, a systematic review reported only 5 articles describing FW-CD treated by rTMS (Table 1$){ }^{13}$ using different approaches and protocols. ${ }^{14-18}$ All of these FW-CD cases gained a short-term symptom improvement. Trying to understand the rTMS efficacy in FW-CD has been the objective of an increasing body of literature data, suggesting that focal functional abnormalities in central networks controlling motor cortex activity may play a role in the etiology of FW-CD, ${ }^{10}$ thus gaining positive effect by rTMS. The mechanisms of action by which rTMS seems to be really effective in these patients have been explained by the combined physiological, neurophysiological and neuromodulatory induced effects. ${ }^{13}$ Considering the physiological aspects of the rTMS, the crucial effect of supra-threshold rTMS is related to the individual's perception of the movements of their paralyzed limb induced by an external trigger, making them aware of the possibility of regaining the function. Furthermore, TMS exerts an additional placebo effect, especially if the information and the style used to inform the patients about the beneficial effects of this treatment strategy and purpose have been properly described. ${ }^{13}$

The neurophysiological mechanism of action of the rTMS has been supported by an increasing body of literature data, suggesting that focal functional abnormalities in central networks may be related to an unbalance between motor intention and motor execution or an overactive self-monitoring with enhanced limbic neural activity, which interferes with movement planning, beginning within the frontal regions and thereby disrupting motor execution. ${ }^{19}$ Moreover, functional-imaging methods demonstrated enhanced neural activity within the anterior cingulate area or orbito-frontal cortex and reduced neural activity within prefrontal motor areas during movement execution of the paralyzed limb in FWCD patients. ${ }^{20}$ These abnormal activation patterns can be the cause of the unconscious inhibition of movement planning and execution.

Finally, it has also been reported that, considering the neuromodulatory induced rTMS effects, a short-lasting rTMS protocols might not cause a durable change in cortical activity, whereas long-lasting changes in cortical neuro-plasticity might only be induced performing longer protocols (e.g., for one or more weeks), thus leading to long-term potentiationusing high-frequency $(>1 \mathrm{~Hz})$ or long-term depression-like changes using low-frequency $(\leq 1 \mathrm{~Hz}){ }^{14}$

Notably, in this case, we objectively documented the improvement using objective outcome measures (i.e. gait analysis) that lacks in the previous reported studies.

In our case, having obtained positive, objectively, and stable effects from r-TMS, we can postulate that our rTMS protocol, combined with a multidisciplinary approach (including a psychological and sexuological support) may be beneficial for symptoms improvement.

\section{REFERENCES}

1. American Psychiatric Association. Diagnostic and Statistical Manual of Mental Disorders, DSM-5 (5th Ed). Arlington; 2013.

2. Nielsen G, Stone J, Edwards MJ. Physiotherapy for functional (psychogenic) motor symptoms: a systematic review. J Psychosom Res 2013;75: 93-102.

3. Voon V, Lang AE. Antidepressant treatment outcomes of psychogenic movement disorder. J Clin Psychiatry 2005;66:1529-1534.

4. Moene FC, Spinhoven P, Hoogduin KA, van Dyck R. A randomised controlled clinical trial on the additional effect of hypnosis in a comprehensive treatment programme for in-patients with conversion disorder of the motor type. Psychother Psychosom 2002;71:66-76.

5. Lefaucheur JP, André-Obadia N, Antal A, Ayache SS, Baeken C, Benninger $\mathrm{DH}$, et al. Evidence-based guidelines on the therapeutic use of repetitive transcranial magnetic stimulation (rTMS). Clin Neurophysiol 2014;125:2150-2206.

6. Greene RL. The MMPI-2: An Interpretive Manual. Needham Heights, MA, USA: Allyn \& Bacon; 2000.

7. Hamilton M. A rating scale for depression. J Neurol Neurosurg Psychiatry 1960;23:56-62.

8. Lienhard K, Schneider D, Maffiuletti NA. Validity of the Optogait photoelectric system for the assessment of spatiotemporal gait parameters. Med Eng Phys 2013;35:500-504.

9. Carson AJ, Brown R, David AS, Duncan R, Edwards MJ, Goldstein LH, et al. Functional (conversion) neurological symptoms: research since the millennium. J Neurol Neurosurg Psychiatr 2012;83:842-850.

10. Liepert J, Hassa T, Tüscher O, Schmidt R. Abnormal motor excitability in patients with psychogenic paresis. A TMS study. J Neurol 2009;256: 121-126.

11. Jellinek DA, Bradford R, Bailey I, Symon L. The role of motor evoked 
potentials in the management of hysterical paraplegia: case report. Paraplegia 1992;30:300-302.

12. Powell TY, Boonstra TW, Martin DM, Loo CK, Breakspear M. Modulation of cortical activity by transcranial direct current stimulation in patients with affective disorder. PLoS ONE 2014;9:e98503.

13. Schönfeldt-Lecuona C, Lefaucheur JP, Lepping P, Liepert J, Connemann BJ, Sartorius A. Non-Invasive Brain Stimulation in Conversion (Functional) Weakness and Paralysis: a Systematic Review and Future Perspectives. Front Neurosci 2016;10:140.

14. Schönfeldt-Lecuona C, Connemann BJ, Viviani R, Spitzer M, Herwig U. Transcranial magnetic stimulation in motor conversion disorder: a short case series. J Clin Neurophysiol 2006;23:472-475.

15. Chastan N, Parain D. Psychogenic paralysis and recovery after motor cortex transcranial magnetic stimulation. Mov Disord 2010;25:15011504.

16. Parain D, Chastan N. Large-field repetitive transcranial magnetic stimulation with circular coil in the treatment of functional neurological symptoms. Neurophysiol Clin 2014;44:425-431.

17. Gaillard A, Gaillard R, Mouaffak F, Radtchenko A, Lôo H. Case report: electroconvulsive therapy in a 33-year-old man with hysterical quadriplegia. Encephale 2012;38:104-109.

18. Broersma M, Koops EA, Vroomen PC, Van der Hoeven JH, Aleman A, Leenders KL, et al. Can repetitive transcranial magnetic stimulation increase muscle strength in functional neurological paresis? A proofofprinciple study. Eur J Neurol 2015;22:866-873.

19. Voon V, Brezing C, Gallea C, Hallett M. Aberrant supplementary motor complex and limbic activity during motor preparation in motor conversion disorder. Mov Disord 2011;26:2396-2403.

20. Stone J, Zeman A, Simonotto E, Meyer M, Azuma R, Flett S, Sharpe M. FMRI in patients with motor conversion symptoms and controls with simulated weakness. Psychosom Med 2007;69:961-969. 